\title{
SURVEY OF FEMALE FOOTBALL REFEREES ABOUT THEIR PHYSICAL CONDITION
}

\author{
Hristiyana Guteva
}

National Sports Academy "Vassil Levski"

\begin{abstract}
Summary
The referees appreciate the importance of the physical training so they consider the assistance of a fitness coach as necessary, yet a small number of them use the services of such a coach. Emphasis on the physical training during the preseason preparatory period, which is a good basis for success at the upcoming matches and passing the fitness tests. The female referees pay attention to the warming up before match and training nevertheless is not the same with the cooling down, which is a bad practice that could result in negative consequences such as traumatism. The majority of respondents have no problems passing the fitness tests but they consider the yo-yo test as most difficult compared to the others.
\end{abstract}

Key words: football referees, women, physical preparation, training

\section{Introduction}

Modern football game has high requirements regarding players' physical abilities and condition. These requirements are valid with full force for football referees. In recent years, both women football and refereeing undergo dynamic development. The development of the women football increases the demands on Referees and Referees Assistants due to shorter rest periods and increased ball in play during games. The optimal positioning for decision making is vital and this requires a sound level of football specific fitness. Hence our interest in the female football referees and the level of physical condition.

\section{Aim and Objectives of the study}

The aim of the following study is to analyze the level and attitude of Bulgarian female football referees towards their physical training and fitness tests. The tasks of the survey are:

1. Conducting a survey among Bulgarian female football referees.

2. Analysis of the results of the survey regarding the opinion of referees on their physical condition and fitness preparation.

3. Forming conclusions and recommendations.

\section{Methods}

For the purpose of the study, we made a survey (of 12 questions regarding physical preparation and fitness tests) among 29 referees. Respondents filled out questionnaires with closed questions, some of which had an alternative response, and other menu responses.

All results were presented as percentage.

\section{Results and Discussion}

On the first question "How many times a week do you train?" $62 \%$ from the respondents answered that they train three times a week, $24 \%$ train two times, $7 \%$ one time and 7\% don't train. (Figure 1)

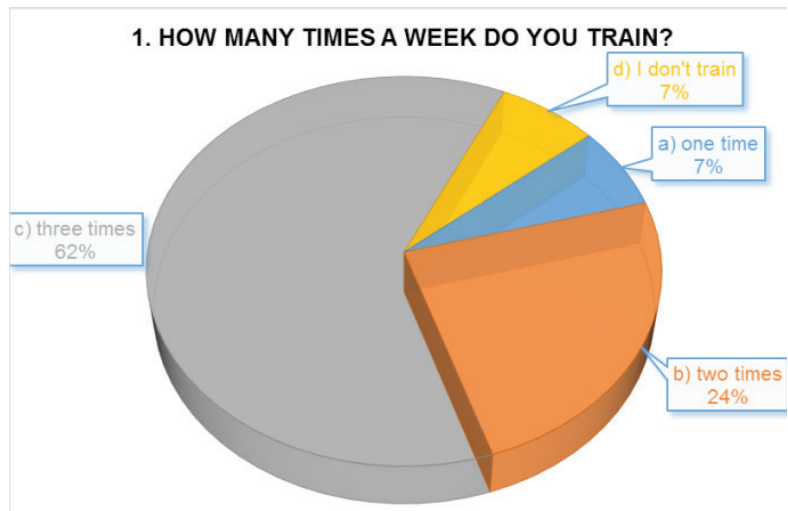

Figure 1.

The next two questions are about the need and use of conditional training coach for football referees.

On the question "Do you use the assistance of a conditional training coach?" $79 \%$ of respondents answered "yes" and $21 \%$ said "no" as a response. (Figure 2)

On the next question regarding conditional training coaches: "Do you need the assistance of a con- 
ditional training coach?" a positive response was given by $62 \%$ of the referees and negative $38 \%$. (Figure 3)

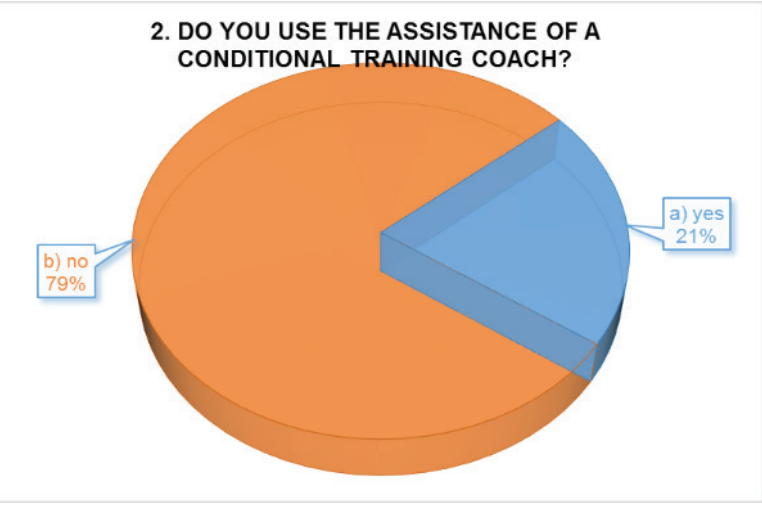

Figure 2.

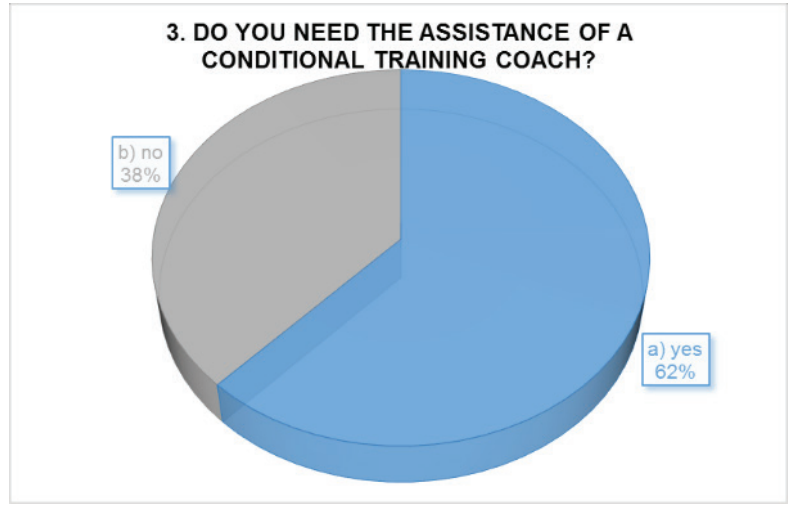

Figure 3.

On the question regarding the average durance of referees' workout, the most frequent answer is one hour, $31 \%$ of the referees' train more than one hour and only $7 \%$ have a workout of less than half an hour. (Figure 4)

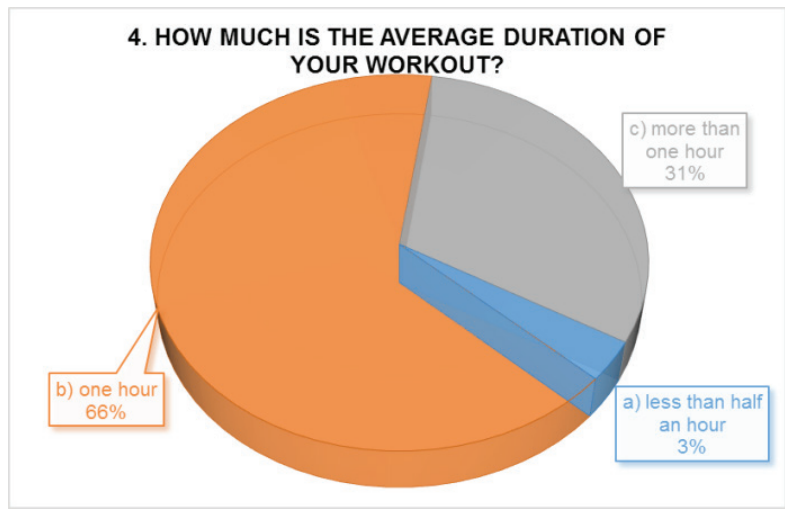

Figure 4.

Question five is "In which period do you spend the most time for physical preparation?" the majority of respondents $73 \%$ answered before the season,
$17 \%$ spend most time for physical preparation during the season and $10 \%$ between the half seasons. (Figure 5)

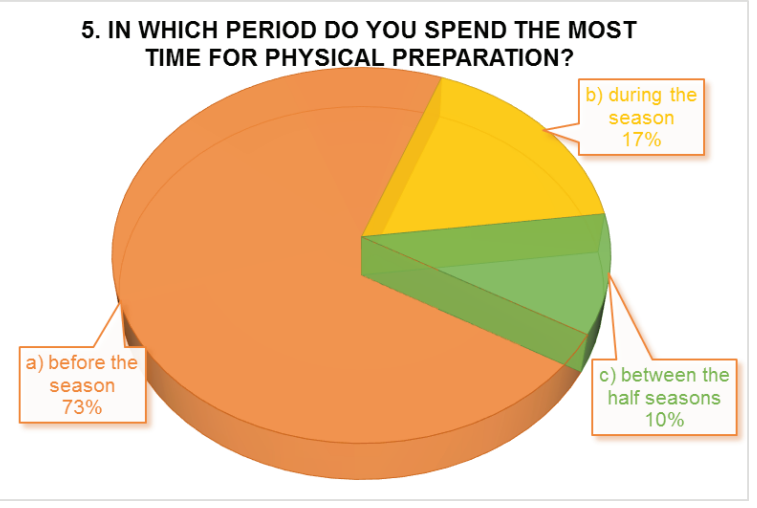

Figure 5.

Question number six is about the duration of the warm-up before match or workout $52 \%$ of the referees answered 15 minutes, almost similar number of respondents has a warm-up more than 15 minutes and 10 minutes, only $7 \%$ do not warm up. (Figure 6)

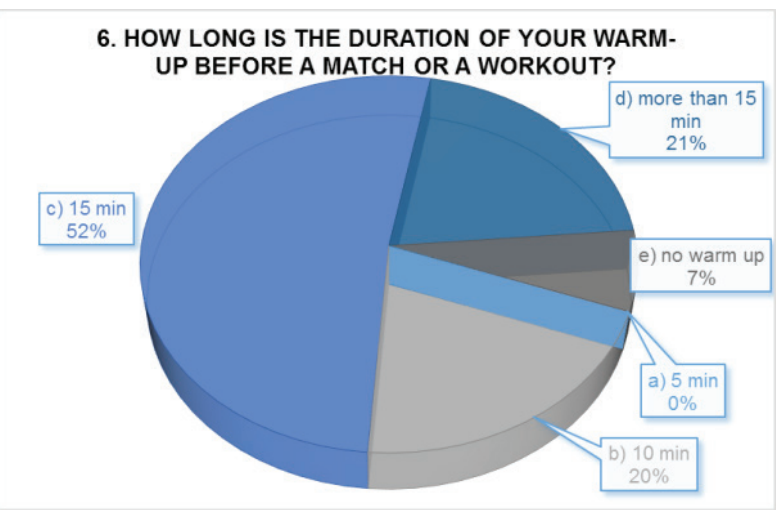

Figure 6.

"What does your warm up contain?" is question number seven and it is possible to indicate more than one answer. The answers jogging and stretching are with close percentage- $26 \%$ and $25 \%$. The running exercises are being used by $23 \%, 17 \%$ also do accelerations but only $9 \%$ do exercises for the movement of the referee and the assistant referee on the field of play. A summary of the answers to the question is presented graphically in Figure 7.

The next question, "What is the focus of your warm up?" has a similar menu of answers like question number seven. The female referees mostly focus on running exercises and stretching with equal percentage $36 \%$. The answer acceleration is selected from $13 \%$ and jogging from $11 \%$. As in the previ- 
ous question the lowest percentage is option e) exercises for the referee and the assistant referee on the field of play, only $4 \%$.

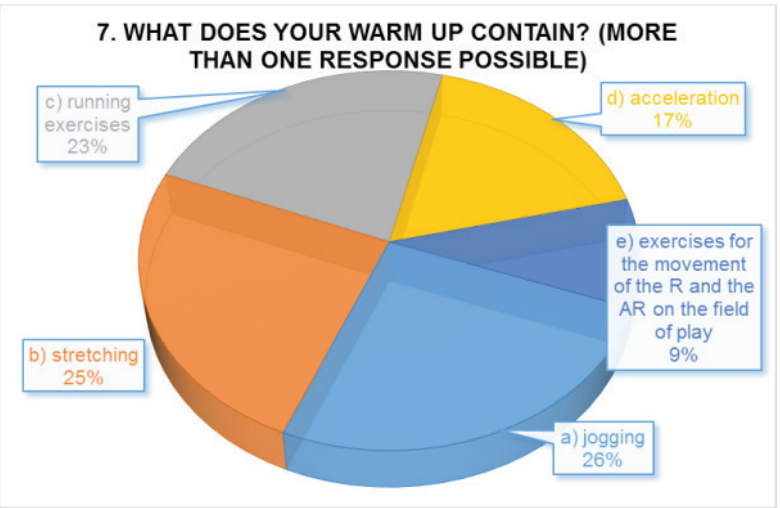

Figure 7.

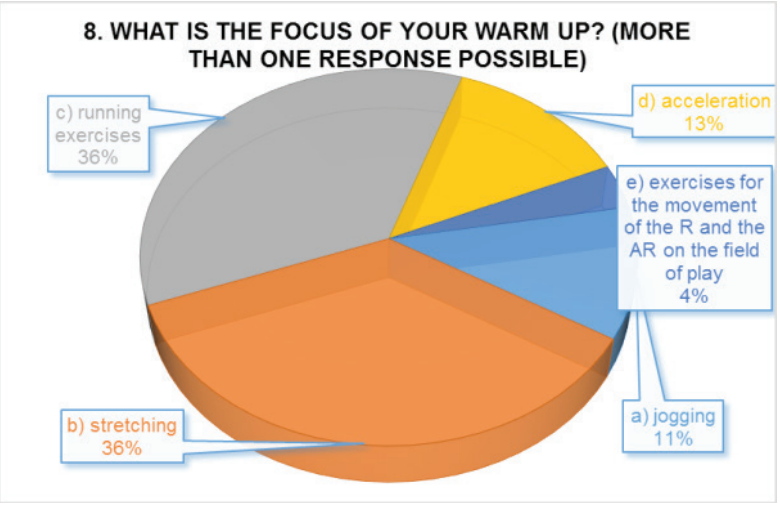

Figure 8.

The next two questions are aimed at workout cool down. On question number nine "Do you cool down after workout?", $90 \%$ of the respondents answer yes, only $10 \%$ of them do not cool down after workout. (Figure 9)

The next question is regarding the cooling down after match. Here 17 referees or $59 \%$ answer with no and 12 referees or $41 \%$ answer with yes. (Figure 10)

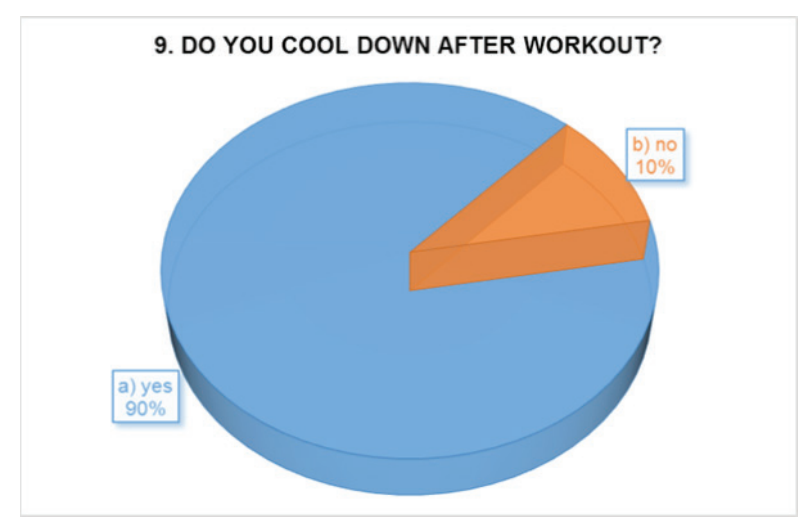

Figure 9.

\section{DO YOU COOL DOWN AFTER MATCH?}

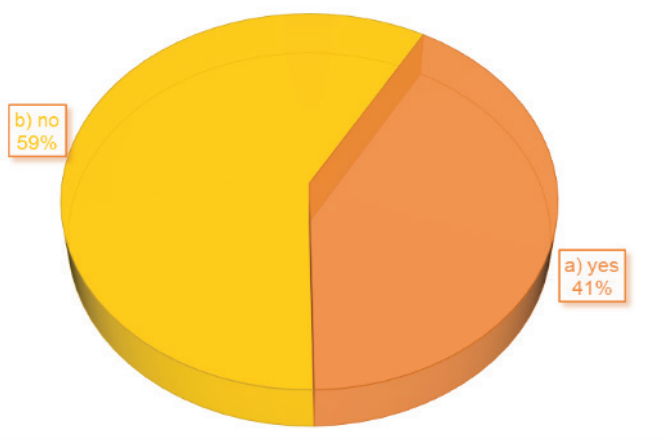

Figure 10.

The last two questions give information about the fitness tests. Question number eleven is "Which is the hardest fitness test?", for $66 \%$ or 19 respondents the yo-yo test is the hardest one, the other $34 \%$ or 10 respondents have chosen the Cooper test. None of the female referees point Test 1 and Test2. (Figure 11)

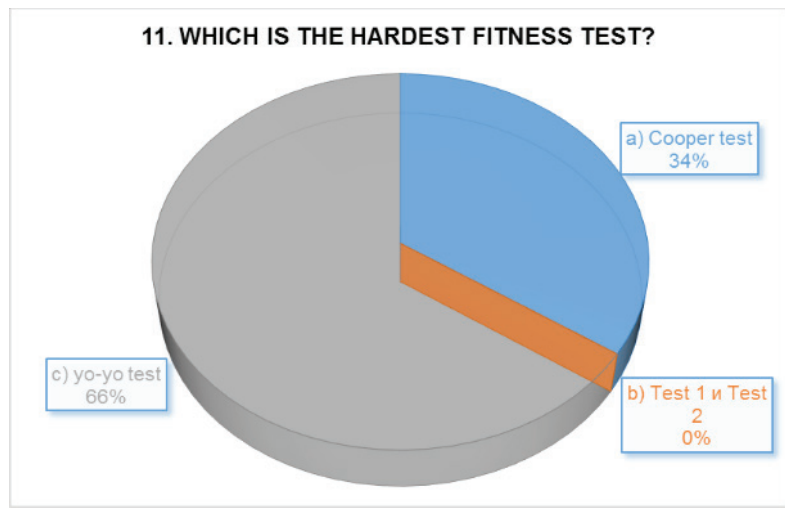

Figure 11.

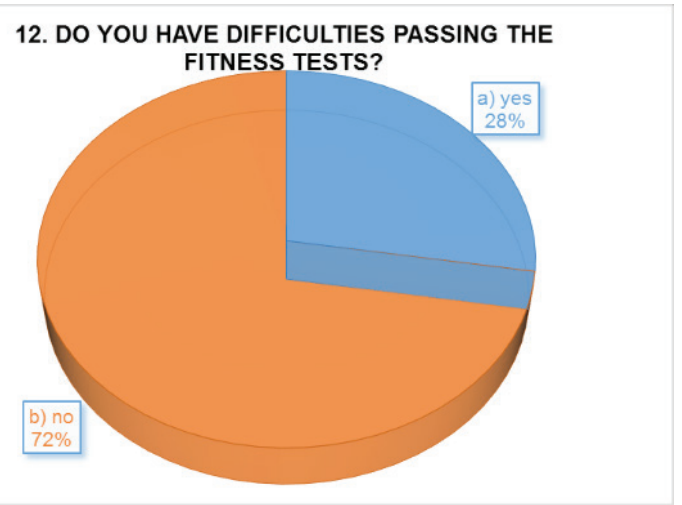

Figure 12.

The last question is "Do you have difficulties passing the fitness tests?". Negative answer is given by $28 \%$ of the referees, the majority $72 \%$ answer negative. (Figure 12) 


\section{Conclusion}

Appling the following survey we revealed the opinion regarding conditioning training and the way Bulgarian women referees prepare physically.

Most of the referees' train three time per week, most of them do not use the help of physical training coach but they answered that such specialist will be very useful. Regarding the duration, most of the respondents' train around one hour. Most women referees highlight the training process before the season, and do not take in mind the training process during the season and between the seasons.

In our opinion more, time must be spent for warmup before the main part of the training session and must include more various exercises. Also negative is the lack of cool down after official matches, which must change.

In respondents' opinion the toughest fitness test is Yo-yo test, but 2/3 of the women referees do not have problem with passing it.

In summary women referees must take into account their physical training during all periods and use wider sets of physical exercises.

\section{References}

Aladjov, K., (2001), Atletizmat vav futbola - vtoro preraboteno izdanie, Tip Top Pres, Sofia.

Aladjov, K., (2007) Morphofunkcionalna sushtnost na fizicheskata podgotovka v sporta, Tip Top Press, Sofia.

Aladjov, K., (2011), Fizicheskata podgotovka v sportnite igri, Simolini 94, Sofia.

Buchvarov, M., L. Dimitrov, A. Gigov, (2008), Futbol presa, kondicia, natisk, NSA Press, Sofia.

Buchvarov, M., (1999), Futbol - integralna fizicheska kondicia, Sofia.

Chervenyakov M., (1997), Aktivizirane dvigatelnata efektivnost na futbolistite, izd. Medicina i fizkultura, Sofia.

Davies, J. A., Brewer, J., (1993) Applied physiology of female soccer players. Sports Med., September, 16(3):1809.

Godik, M.A., A.S.Shishkov, (1983), Kontrol i upravlenie na trenirovuchnoto i sustezatelnoto natovarvane vuv futbola, Medicina i fizkultura, Sofia.

http://gdfra.org.au/4411RefFitnessGuide.pdf

http://www.ffacoachingresource.com.au/media/153215/13078_FOOTBALL_Womens-Football-Development-Guide_Final-for-web_single-pages.pdf http://www.fitness4football.com/fitness4_referees/introduction.htm

Krustrup, P., Mohr, M., Ellingsgaad, H., Bangsbo, J., (2005), Physical Demands during an Elite Female Soccer Game: Importance of Training Status, Institute of Exercise and Sport Sciences, Department of Human Physiology, University of Copenhagen, Denmark, 2 Sports Medicine Research Unit, Copenhagen University Hospital, Denmark., July, 37(7):1242-8.

\section{Author information:}

Hristiyana Guteva, PhD student, National Sports Academy "Vassil Levski”, Department "Track \& Field"

Address: Sofia, Bulgaria, ZIP 1700, "Studentski gard”, NSA "Vassil Levski", office 334 (Department "Track \& Field")

Mobile +359889503 602, e-mail: hris.guteva@yahoo. com 